\title{
HETEROTOPIAS, DISTOPIAS E ARTES AFINS
}

\author{
HETEROTOPIES, DISTOPIES AND RELATED ARTS \\ HÉTÉROTOPIES, DISTOPIES ET ARTS CONNEXES \\ HETEROTOPIAS, DISTOPIAS Y ARTES AFINES
}

\section{Paula Guerra}

Universidade do Porto, Faculdade de Letras e Instituto de Sociologia, CITCEM, CEGOT, Dinâmia'CET, Griffith Centre for Cultural Research, Porto, Portugal

\section{Lígia Dabul}

Universidade Federal Fluminense, Programa de Pós-Graduação em Estudos Contemporâneos das Artes da e do Programa de Pós-Graduação em Sociologia, Rio de Janeiro, Brasil

Após a leitura final deste Volume da Revista Todas as Artes, um conceito emergiu quase de imediato: o de heterotopia. Este conceito foi desenvolvido originalmente por Michel Foucault e surge, muito brevemente, no seu livro As palavras e as coisas (1999 [1966]) numa abordagem discursiva e linguística. Porém, mais tarde, o mesmo conceito volta a emergir numa conformidade espacial. Foucault, com a noção de heterotopia, vem estabelecer uma oposição ao conceito de utopia, que se referia a um conjunto de "sítios" que não possuem um lugar na realidade. Uma heterotopia, pelo contrário, destaca a existência de múltiplos e complexos "sítios" presentes em todas as sociedades. Aliás, Foucault afirma que "todos os outros "sítios" reais que podem ser encontrados dentro da cultura, são simultaneamente representados, contestados e invertidos" (Foucault, 1984: 3). A exemplo de Foucault, reiteradamente começámos a encarar os mundos das artes e os campos artísticos e culturais, como um aglomerado de "sítios" encontrados nas sociedades e que, essencialmente, podem ser tidos como sítios que estão à margem dos lugares, mas compondo a realidade, no sentido em que a representam, a contestam e, subsequentemente, invertem - conferindo-Ihe sentidos à boa maneira weberiana (Weber, 1995 [1921]).

John (1999), numa tentativa de clarificar o conceito de heterotopia cultural alternativa, estabelece um paralelismo com as conceções de Michel Foucault que, no nosso entender, visam retratar um campo artístico e cultural abrangente e não apenas algo in locu ou in situ. Em primeiro lugar, estas heterotopias culturais representam espaços de alteridade - aquilo que Foucault apelida de countersites - em que a ambivalência e a incerteza são dispersas e onde o conhecimento deslocado e rejeitado é celebrado, basta ter como exemplo todas as formas artísticas que não são reconhecidas institucionalmente. Se pensarmos bem, os processos de artificação contemporâneos (Shapiro, 2019) são, na verdade, heterotopias. Um segundo ponto diz respeito ao facto de serem espaços heterogéneos, nos quais se conjuga uma espécie de justaposição da simultaneidade da diferença (Soja, 1995). Além disso, são também espaços contestados e espaços de contestação, no sentido em que as práticas que neles são levadas a cabo, refletem processos de (re)criação de identidades (Guerra, 2020a) e tantas vezes de mobilizações em torno da subversão de sua ordem (Marcondes, 2020). Em que sentido é que esta informação se adequa a uma análise sociológica sobre os campos artísticos? As heterotopias da crise, propostas por Foucault (2015) consistem em formas de analisar o campo sociológico, com o objetivo de se compreender o relacionamento entre espaços existentes, dentro de um mesmo campo, consigo mesmos. É a partir deste entendimento 
que obtemos conceções sobre a vida dos indivíduos, sobre as transformações sociais e acerca das implicações no campo criativo, artístico e cultural.

Como colocado em Guerra (2020b), Bolaños (2007), no sulco da estética da redenção de Adorno (2003), substancializa o papel crítico da arte na sociedade: confirmando que a arte é mais do que entretimento; a arte participa no devir da sociedade e da cultura sempre como contraponto criativo reflexivo. Por isso a imaginação artística é heterotópica e distópica. A distopia coincide com "uma inversão paródica da utopia tradicional com a sátira da sociedade contemporânea" (Ferns, 1999: 105), baseadas em preocupações éticas e políticas sobre tendências sociopolíticas que poderiam transformar o mundo contemporâneo. Alinhadas com os tempos pandémicos em que vivemos, heterotopias e distopias apresentam-se neste Volume em catadupa. Para uma visão geral deste Número, propomos uma apropriação da ótica do espelho. Trata-se de uma ilusão em que, simultaneamente, são projetadas duas realidades no mesmo espaço e no tempo. Trata-se da visão de quem projeta a realidade e de quem a vê. A arte e a cultura - e a visão sobre elas - podem ser lidas a partir desta ótica. Basta lermos os contributos desta revista para ver como uma realidade é projetada - pela palavra e pela imagem - e como é entendia - por quem a lê. No mesmo espaço, no mesmo tempo, nas mesmas criações artísticas. Outras duas heterotopias da teoria foucaultiana vinculam-se ao tempo. A permanência e o consumo do tempo. É aqui que encontrámos os pontos de convergência, na atemporalidade. A arte e a cultura são tempo em permanência, e materializações como museus, pinturas, manifestações culturais, totens, entre outros elementos, personificam o valor da sociedade humana: o conhecimento sobre ela (Junior, 2016) e sua episteme.

As heterotopias são intrínsecas à existência individual e coletiva. Unem espaços reais e irreais, bem como os transcendem. O mesmo acontece com as distopias. Sajjad e Perveen (2019), numa análise de My Name is Red [O meu Nome é Vermelho] de Orhan Pamuk (2001), enunciam que o campo artístico pode ser explorado como um terceiro espaço, uma vez que este compreende e comporta um conjunto de características e de princípios que se desviam do tempo, enquanto que, simultâneamente, existem no mundo real. De facto, o espaço artístico e o espaço cultural, são analisados como sendo representativos, contestatários e subversivos das tradições mainstream. $\mathrm{Na}$ verdade, não existe uma linha impenetrável que separe diferentes formas de expressão artística. Gurses (2013) defende que a pintura e a escrita não são tão distantes quanto se pensa. Tal como a música não difere largamente da escultura. Tratam-se apenas de um conjunto de escolhas que são criadas, através dos espaços, e que desafiam o status quo dos espaços dominantes da civilização (Elias, 1989).

Dentro desta abordagem, o primeiro artigo deste volume é da autoria de Nancy Duxbury e intitula-se Mapeamento cultural. Enfrentar desafios de políticas de planeamento culturais mais participativos e pluralistas. Trata-se da apresentação de um campo de investigação pautado pela interdisciplinaridade e que visa a criação de uma praxis geradora de conhecimentos que, essencialmente, facilitem o planeamento e o desenvolvimento participativo/co-criativo. Ao mencionar que os espaços incorporam histórias multivocais, o eu coletivo de natureza claramente heterotópica assume destaque nesta publicação. Texto marcante que assinala uma trajetória de investigação brilhante em torno das atividades culturais e criativas na contemporaneidade. De seguida, e em outros espaços, outras heterotopias, Robin Kuchar apresenta Music venues in transition: States of Autonomy, Dependence and Subcultural Institutionalization. Este sociólogo 
alemão analisa como as transformações dos ambientes socioespaciais exercem influência sobre os locais de música que, originalmente, foram desenvolvidos numa lógica do-it-yourself. Estamos, assim, perante um artigo que convida à compreensão dos "sítios" enquanto atores individuais que se desenvolvem em função de estratégias espaciais e culturais coletivas. Sem dúvida, um artigo central deste Volume que assinala o primeiro artigo resultante do inovador e instigante doutoramento de Robin Kuchar. Sempre com o espaço no horizonte, também assinala o facto de este sociólogo se ter tornado recentemente residente não só de Lueneburg mas do Porto cruzando espaços, tempos, pessoas, sociabilidades, redes, afetos, diásporas.

De seguida, Cynthia Carvalho Martins e Camila do Valle vêm dar conta dos processos de construção da identidade de artistas de rua, partindo do caso "A Vida é uma Festa". Neste artigo são abordadas diversas disciplinas do campo artístico e cultural, tais como a música, as artes plásticas, o teatro, a literatura e outras, ao passo que se reflete sobre as manifestações que resultam da conjugação dessas mesmas dimensões, implicando uma reconstrução identitária artística compósita incorporada nos artistas de rua. Abrindo caminho à distopia, Júlia Almeida de Mello apresenta-nos o seu artigo intitulado Revisitando o Grotesco: $O$ indefinível como transgressão na arte. A autora analisa e enfatiza o grotesco enquanto elemento subversivo aos cânones artísticos institucionalizados, enquanto estabelece simultaneamente uma analogia com outras dimensões do eu, tais como o género, as políticas de identidade e, claro está, as resistências. Vem, assim, revelar uma outra faceta da arte contemporânea.

Cíntia Sanmartin Fernandes e Micael Herschmann, com o seu contributo Efervescências musicais e noturnidades no beco das artes, discutem a ambiência que pauta a noturnidade e as festas que nela decorrem. Neste artigo, a questão do tempo (como já foi abordado) emerge como um elemento intrínseco às experiências e às expectativas, mas também às interações. Estamos perante uma análise sobre a construção de um imaginário da urbe e das experiências culturais que, concludentemente, ocasionam segmentos de atores sociais que se interligam a partir da produção musical recriando tempos, espaços e sociabilidades. Cândido Alberto da Costa Gomes foca o desenvolvimento da adolescência em condições adversas - como o próprio refere - centrando-se no genocídio. Aqui a autoexpressão artística, como os relatos literários de Anne Frank sustentados pelas teorias simmeliana e foucauliana são a base para o entendimento destes não lugares. De heterotopias. De distopias. Ambas no Anexo Secreto.

Ainda ao espelho, Rosiane Neves em Novas perspetivas: Moda \& envelhecimento, vem dar a conhecer as diversas representações sociais da mulher na velhice, tendo como base o mundo da moda. O discurso na primeira pessoa é o que demarca este artigo, fazendo com que o mesmo nos confira uma visão sobre as representações sociais sobre moda para mulheres idosas. Algo tanto mais premente se pensarmos na sociedade portuguesa. Sofia Sousa, com o registo de pesquisa Lead by Example. Conversa com Mundo Segundo oferece-nos a visão de um dos mais ativos embaixadores do movimento hip-hop em Portugal, nomeadamente Mundo Segundo, sobre questões relacionadas com as práticas artísticas e as intervenções sociais. Além do seu percurso, problemáticas da atualidade como a pandemia da COVID-19, o music-making e a intervenção social por via das artes, foram tópicos de discussão.

Nathanael Araújo e Ana Paula da Costa apresentam uma conversa com Martyn Lyons, um Professor Emérito de História e Estudos Europeus, especialista nos séculos XIX e XX e que, ao longo 
do seu percurso académico, se focou na investigação da história do livro, leitura e escrita, mas também história francesa e história australiana. Neste registo de pesquisa, temos patente algo que foi anteriormente referido, a atemporalidade do conhecimento. Por fim, Pedro Quintela presenteia-nos com Justiça social, Igualdade e Equidade no Setor Cultural e Criativo: uma resenha do livro homónimo de Mark Banks. Aqui, todas as urgências heterotópicas e distópicas emergem, mostrando a importância da imaginação artística como crítica analítica da sociedade contemporânea.

Porto e Rio de Janeiro, setembro de 2020.

\section{REFERÊNCIAS BIBLIOGRÁFICAS}

Adorno, Theodor W. (2003). Sobre a indústria da cultura. Coimbra: Angelus Novus.

Bolaños, Paolo (2007). The critical role of art: Adorno between utopia and dystopia. Kritike: An Online Journal of Philosophy, 1(1), pp. 25-31.

Bosman, Frank G. (2014). The Lamb of Comstock: Dystopia and religion in video games. Heidelberg Journal of Religions on the Internet, v. 5, pp. $162-182$.

Elias, Norbert (1989). O processo civilizacional. 2 vols. Lisboa: Dom Quixote.

Ferns, Chris (1999). Narrating utopia. Ideology, gender, form in utopian literature. Liverpool: Liverpool University Press.

Foucault, Michel (1984). Architecture /Mouvement/ Continuité. Retirado de: http://web.mit.edu/allanmc/www/foucault1.

Foucault, Michel (2015). Ditos e escritos, vol.III - estética: literatura e pintura, música e cinema. Rio de Janeiro: Forense Universitária.

Foucault, Michel. (1999 [1966]). As palavras e as coisas. São Paulo: Martins Fontes.

Guerra, Paula (2020a). A margem é onde tudo começa e onde tudo acaba. A. Dasilva O. fala ao país pela Rádio Caos. Travessias, 14(2), pp. 105-124.

Guerra, Paula (2020b). Sereias distópicas: um ensaio sobre a relevância da distopia nas criações artísticas contemporâneas portuguesas. Arte e Ensaios, Rio de Janeiro, PPGAV-UFRF, 26(40), pp. 393-407.

Gurses, Hande (2013). Fictional displacements: An analysis of three texts by Orhan Pamuk. London. University College London.

John, Grahram St. (1999). Alternative cultural heterotopia: ConFest as Australia's marginal centre. Vitoria: La Trobe University, Bundoora, Faculty of Humanities and Social Sciences.

Junior, Dirceu Arno Krüger (2016). Foucault: A Heterotopia como Alternativa para Pensar o Espaço Social. Enciclopedia Pelotas, vol.5, pp. 22-37.

Marcondes, Guilherme (2020). Conexões de cura na arte contemporânea brasileira. Arte e Ensaios, Rio de Janeiro, PPGAV-UFRJ, 26(40), pp. 375-391.

Sajjad, Noor-ul-Ain; Perveen, Ayesha (2019). Private heterotopia and the public space: An incongruity explored through Orhan Pamuk's My Name Is Red. Sage Open, pp. 1-8.

Shapiro, Roberta (2019). Artification as process. Cultural Sociology, 13 (3), pp. 265-275.

Soja, Edward. (1996). Thirdspace: Expanding the geographical imagination. Malden: MA: Blackwell.

Weber, Max (1995) [1921]. Os fundamentos racionais e sociológicos da música. São Paulo: EDUSP.

Paula Guerra. Doutora em Sociologia. Professora de Sociologia da Faculdade de Letras e Investigadora do Instituto de Sociologia da Universidade do Porto. Professora Adjunta no Griffith Center for Social and Cultural Studies na Austrália. Investigadora colaboradora no Centro de Investigação Transdisciplinar «Cultura, Espaço e Memória», no Centro de Estudos de Geografia e Ordenamento do Território e no DINÂMIA'CET-IUL - Centre for Socioeconomic Change and Territorial Studies, Portugal. Faculdade de Letras da Universidade do Porto, Via Panorâmica, s/n, 4150-564 Porto, Portugal. E-mail: pguerra@letras.up.pt. ORCID: 0000-0003-2377-8045.

Lígia Dabul. Doutora em Sociologia. Professora Colaboradora dos Programas de Pós-Graduação em Sociologia e em Estudos Contemporâneos das Artes da Universidade Federal Fluminense. Coordenadora do Nectar/UFF - Núcleo de Estudos Cidadania, Trabalho e Arte da Universidade Federal Fluminense. Poeta. Universidade 
Federal Fluminense, R. Miguel de Frias, 9 - Icaraí, Niterói - RJ, 24220-900, Brasil. E-mail: ligia.dabul@gmail.com. ORCID: 0000-0002-6224-9720.

\section{Citação:}

Guerra, Paula \& Dabul, Lígia (2020). Heterotopias, distopias e artes afins. Todas as Artes. Revista Luso-

brasileira de Artes e Cultura, 3(2), pp. 4-8. ISSN 2184-3805. DOI: https://doi.org/10.21747/21843805/tav3n2het 